Bond University

Research Repository

\title{
Sustainability management teaching resources and the challenge of balancing planet, people, and profits
}

Aragon-Correa, J. Alberto; Marcus, Alfred A.; Rivera, Jorge E.; Kenworthy, Amy L.

Published in:

Academy of Management Learning and Education

DOI:

10.5465/amle.2017.0180

Licence:

CC BY-NC-ND

Link to output in Bond University research repository.

Recommended citation(APA):

Aragon-Correa, J. A., Marcus, A. A., Rivera, J. E., \& Kenworthy, A. L. (2017). Sustainability management teaching resources and the challenge of balancing planet, people, and profits. Academy of Management Learning and Education, 16(3), 469-483. https://doi.org/10.5465/amle.2017.0180

\section{General rights}

Copyright and moral rights for the publications made accessible in the public portal are retained by the authors and/or other copyright owners and it is a condition of accessing publications that users recognise and abide by the legal requirements associated with these rights.

For more information, or if you believe that this document breaches copyright, please contact the Bond University research repository coordinator 


\title{
Sustainability Management Teaching Resources and the Challenge of Balancing Planet, People, and Profits
}

\author{
J. ALBERTO ARAGON-CORREA \\ University of Granada, Granada, Spain, University of Surrey, United Kingdom
}

ALFRED A. MARCUS

University of Minnesota, Minneapolis, United States

JORGE E. RIVERA

The George Washington University, Washington, DC, United States

AMY L. KENWORTHY

Bond University, Gold Coast, Queensland, Australia

\begin{abstract}
Over the past decade, there has been a notable increase in discussions surrounding the integration of global sustainability issues and responsible management practices into the business school curriculum. What we have yet to see, however, and what we would like to begin with this essay, is a meaningful discussion regarding the overarching goals of sustainable and responsible management education as they relate to the available teaching and learning resources in this domain. To achieve this, we first identify the tensions between teaching sustainability to change the world for the better and those aimed at making companies better off. We propose a balance between these two aspirations. We then turn to the thoughts of academic practitioners in the field with a survey of 169 management and sustainability instructors. Results indicate that respondents use papers, cases, and videos to teach courses in this field, while textbooks and electronic resources (i.e., databases, simulations, and apps) are only marginally utilized. The respondents are only moderately satisfied with most of the available teaching resources and the integration of existing resources within general curricula. The results show some interesting differences between postgraduate and undergraduate courses, and also between junior and senior instructors. In this essay, we argue that the moral enthusiasm for teaching in the sustainability domain must not take away from precise analysis of problems, solutions, their implementability, and their interconnected complexity. As such, we propose a set of five recommendations for the design and selection of sustainability management teaching resources that will effectively address issues related to planet, people, and profits.
\end{abstract}

With regard to sustainability, gaps exist both in the world of practice and the world of teaching. Within the world of practice, gaps occur in the degree to which managers are implementing sustainability in their firms. Experts at McKinsey and Co. estimate that only $20 \%$ of companies in the S\&P 500 report having explicit, long-term sustainability goals, with a further $50 \%$ reporting no sustainability goals at all (Bonini \& Swartz, 2014). Although 75\% of senior executives in investment firms maintain that sustainability 
performance is materially important to the investment decisions they make, only $60 \%$ of managers in companies believe that sustainability practices affect their decisions (Unruh et al., 2016). Within the world of teaching, there are also serious gaps with regard to sustainability. Business school faculty and administrators should, at the very least, keep pace with sustainability and the ethical concerns in society. Ideally, we do more than that-we become frontrunners in the research, dissemination, and implementation of ethically driven sustainable practices. Yet it appears that there is a large gap between our ideal impact on the business community and the associated practices and outcomes we see there. Managers still assert the reasons that their companies are not more sustainable are that most of them do not know how to evaluate the materiality of sustainability issues, communicate their sustainable concerns with stakeholders, organize their sustainable sourcing, or effectively carry out many other sustainabilityrelated activities (Laughland \& Bansal, 2011).

A growing number of instructors and schools have been trying to reinforce the sustainable dimension in their management courses despite the multiple internal barriers to integrating sustainable education there (Delgado-Ceballos, Aragón-Correa, Ortiz-deMandojana, \& Rueda-Manzanares, 2012). However, teaching resources in this field still are relatively new, and it is unclear if and how they are helping in this process. As a way to move the field forward, and as a complement to this essay, we edited the Book and Resource Review (BRR) collection on teaching resources in the field of management and sustainability published here. The collection contains a diverse array of relevant and easily accessible teaching resources drawn from across a variety of resource types, including textbooks, practitioner books, cases, simulations, videos, online databases, and mobile phone applications (apps).

As fodder for our comments here and to assist with resource selection for the BRR collection, we conducted a survey of management academic instructors in the field of sustainability from which we obtained 169 responses. In the survey, we asked a number of questions about the importance of teaching resources such as textbooks, cases, and videos as well as information regarding instructor satisfaction with these resources. Among many of the instructors we surveyed, the moral imperative of changing the world for the better has eclipsed the pragmatic imperative of improving company performance. Almost $77 \%$ of respondents agreed or strongly agreed with the statement "resources to teach in this field should specially aim to change the world for the better," whereas only $44 \%$ of respondents agreed or strongly agreed with the statement "resources to teach in this field should specially aim to make companies better off."

The tension between changing the world for the better and improving company financial performance is inextricably tied to the teaching of sustainability and the teaching tools that exist for this purpose. Exploring this tension is critical to moving education in the sustainability domain forward, and thus, it is a theme woven throughout this essay. It is imperative that we work to create engaging, innovative, and effective teaching materials that both provide a business case for sustainability as well as illustrate the moral and ethical imperatives tied to sustainable business practices. How we do this is the question at hand. Following a discussion of what the ideal aim of sustainability-oriented teaching resources should be, we explore the tension that exists in instructors' views of existing teaching resources for sustainability, present the results of our survey, comment on the results, and conclude with a call to action in terms of a comprehensive set of five recommendations for the evaluation, selection, and design of teaching resources in the sustainability management domain.

\footnotetext{
"The tension between changing the world for the better and improving company financial performance is inextricably tied to the teaching of sustainability and the teaching tools that exist for this purpose."
}

\section{CHANGING THE WORLD FOR THE BETTER SHOULD BE THE AIM OF TEACHING RESOURCES IN MANAGEMENT AND SUSTAINABILITY}

Agreement with the statement "sustainability teaching resources should aim to teach the world for the better" is very high in our sample of management instructors $(77 \%$ agree or strongly agree with this statement). Junior professors (less than 8 years of teaching experience) are more inclined to agree with the statement that resources to teach sustainability should specially aim to change the world for the better (86\% agree or strongly agree with the "changing 
the world" statement), yet a still relevant 685 of the senior professors (those with 8 or more years of teaching experience) also agree with it. We assume that many of the students who enroll in classes on sustainability are also drawn to the topic because of their desire to change the world for the better.

Thus, it stands to reason that instructors teaching sustainability and management mostly expect that the teaching resources in this field should be focused on the moral imperative of making the world a better place. We share the view that resources for teaching sustainability should provide sharp and compelling analyses of global environmental and social responsibility issues and problems of great importance. The global problems that sustainability represents are urgent and include working conditions, discrimination, climate change, preservation of the world's water resources, income, jobs, and much more. There can be no doubt that today, more than ever before, we need informative, engaging, and effective teaching material that both inspires management students and provides them with concrete tools and techniques to tackle these and other moral challenges to making the world a better place (Dyllick, 2015).

Yet, in our view, effective teaching material in the sustainability domain must also be precise in presenting the kinds of problems that need to be addressed and so do specific solutions that might be available. For instance, the transition from a global economy based less on fossil fuels to one based more on renewable energy has many compelling reasons including the finite nature and potential exhaustion of existing fossil fuels, the damage they cause human beings, the environment in the form of conventional pollution and climate change, and the disproportionate amount of the reserves found in states with repressive governments. Each issue has a different sense of urgency. Each introduces its own timetable. Each must be considered. Given these differences, the variety of potential solutions-including solar, wind and tidal energy, biofuels, efficiency, and geothermal, among others-must be discussed and given over to systematic comparison. Such an analysis might end in consideration of the implementability of various solutions by the collective actions of different groups of organizations in society. How these solutions are implemented have different managerial implications that must also be considered.

In addition, we must not lose sight of the subtle manifestation of the issues that drives sustainability to the forefront. Population growth in the world today is highly skewed. While Europe, Japan, China, and to some extent the US have aging populations that enjoy relatively very high consumption levels, most of Africa and many of the nations in the Middle East continue to have rapidly growing populations and youth bulges. This division has created huge problems, with stress on the ecology arising from both overconsumption in wealthy nations and the need to support burgeoning populations in developing ones. This adverse dynamic is also exacerbated by an accompanying lack of economic growth to create sufficient jobs, mass population movements, ideological extremism, and violence. Moreover, as well-educated and wealthy segments of industrialized countries' populations are aging, poorer and younger segments from developing nations are engaged in mass migrations to find opportunities and escape violence. They face extreme backlash from native populations in the industrialized world. This backlash is destabilizing world politics.

Further, we consider it important that issues be considered in all their interconnected complexity. For instance, feeding the planet is on essential issue that motivates the study of sustainability. However, this issue is not just about increasing agricultural productivity in an environmentally sound manner. It also involves the distribution of the world's food resources and the impact of that distribution on human health. In 2000, Worldwatch Institute, a Washington, DC-based think tank, announced that for the first time in human history, the number of underweight and of overweight people was about equal (Gardner \& Halweil, 2000). Since 1980, the world's underfed population had declined to roughly 1.1 billion, while the number of overweight people had increased to about 1.1 billion. Both groups had high levels of sickness and disability, curtailed life expectancies, and low productivity levels. Both suffered, whether from a lack of the essential nutrients and dietary elements a person needs for healthy living. Clearly, while many people are starving in the world, some people are overfed, and world population is still growing. To make matters worse, we now have data from the Food and Agriculture Organization of the United Nations (2016) that about one third, or approximately 1.3 billion metric tons, of all food produced for human consumption is wasted every year (Dreibelbis, 2013). To put this into a financial context, researchers from the U.S. Department of Agriculture estimated that the value of food loss, including retail and consumer waste, was U.S. $\$ 165.6$ billion in 2008. This equaled roughly \$544 in 
food loss per person per year. When looking specifically at the consumer level, individuals wasted approximately $10 \%$ of the food purchased annually (Buzby \& Hyman, 2012). As this illustrates, both the mal-distribution of food and misuse of its consumption are important and complex issues. One should not be discussed without the other, and both need to be addressed in the context of sustainability education and global change. To further illustrate the complexity of these issues and the challenge they present in the educational context, we know that climate change is severely impacting agriculture and global food security. Yet, at the same time, recent research reveals that the agriculture sectors contribute to climate change, with $21 \%$ of all emissions. This information, as presented at a global forum in October 2016 by representatives from the FAO, led key members of the organization to declare "business as usual is not the answer." People in the world are technologically sophisticated, but they also are divided into belligerent groups that make it hard for us to take collective action and sensibly manage such complex and seemingly intractable issues.

A full array of such questions is discussed today in the world, under the rubric of sustainable development, including the adequacy of the world's food supplies, drought, water shortages, disease, education, human rights, and poverty. The data are clear. These issues are dire. From a moral or normative perspective, there can be no doubt that the obligation to change the world for the better is absolute, and whether it "pays" to do so is only partly relevant. However, management instructors not only need to put emphasis on the priority of moral imperatives, they must also discover and develop ways to make meeting these obligations possible, and, even better, attractive for companies. We do not wish to take away from the moral enthusiasm brought to this subject matter by instructors, but we also want instructors to emphasize ways that increase the chances that companies will implement and uphold worldchanging policies and strategies that are not only in their interest but also, and more important, in the interest of us all. Going this route necessitates that management teaching resources are developed with the aim of encouraging students to sufficiently engage in precise analysis of problems and possible solutions, the implementability of solutions, their interconnected complexity, and the social, environmental, economic, and managerial impact associated with their outcomes.
THE BUSINESS CASE FOR SUSTAINABILITY MUST ALSO BE AT THE FOREFRONT OF TEACHING AND TEACHING RESOURCES

Simultaneously with highlighting the moral imperative of sustainability in stimulating teaching resources, it is also necessary to create teaching material that makes a business case for sustainability. Some of the world's most prominent scholars in strategy and management have started us down this path. They argue that the world's great sustainability challenges should be seen as opportunities for business and not as threats (e.g., Hart, 1997; Porter \& Van der Linde, 1995; Marcus, 1995) with most researchers in the field adopting a similar win-win perspective (see Van der Byl \& Slawinski's 2015 detailed review of the literature). At the same time that companies create economic value, they should be encouraged to enhance conditions in the broader community. Acting as businesses, and not as charitable givers, they can become powerful forces for maximizing societal benefits as well as advancing their own goals.

We believe that the key to balancing these objectives may be to focus on areas where a company's core business most intersects with the world's environmental and social challenges. If the company is an automaker, that means discovering means of mobility that require less consumption of petroleum and actively commercializing these alternatives. If the company is a food maker, it means movement away from reliance on products rich in sugar, salt, and fat and toward products that are more nutritious and healthier. By reconceiving their business models and tilting their strategies in new directions, it is possible for companies to meet social needs, and at the same time, prosper as business corporations.

Prahalad and Hart (2002) added to this win-win perspective with their emphasis on customers who were the bottom of the pyramid, and most recently London's book (2016) and Hart, Sharma, and Halme's edited special issue (2016) have highlighted how business may be effective alleviating poverty. Focusing on customers at the bottom of the pyramid is in the corporate interest because world economic growth in wealthy nations has for the most part peaked, while the growth rates of nations at the bottom still has vast potential. If corporations can adapt products and services in areas like clean energy, food, education, health care, banking, and telecommunications to meet the needs of the poor, they can gain competitive advantage from higher volume sales and simultaneously encourage local development. For companies, the business case for serving 
these markets is not just the ability to innovate and to lower cost, but companies that succeeded in meeting the needs of the poor also should be able to attract, recruit, and motivate a more talented workforce and gain recognition and reputational advantage.

Meta-analysis of whether it "pays to be good" generally supports the win-win ideas of multiple scholars, but it does not do so unambiguously. For example, Margolis, Effenbein, and Walsh (2011) found an overall positive effect of corporate social responsibility. Companies faced no financial penalty if they "did good;" however, the link from prior financial performance to corporate social performance was stronger than the reverse, suggesting that companies also had to be able to "afford" to do "good."

One of the strongest relationships between corporate environmental performance and corporate financial performance is found in a paper by Eccles, Ioannou, and Serafeim (2014). They assessed the question of whether "it pays to be good" by examining a matched sample of 180 companies that voluntarily adopted environmental and social policies many years ago. The companies made their boards of directors responsible, they provided their top executive with incentives, they had procedures in place for engaging stakeholders, they declared that they were long-term oriented, and they had ways to measure and disclose nonfinancial information. Eccles, Ioannou, and Serafeim (2014) found that these companies significantly outperformed their counterparts over the long term, both in terms of stock market and accounting performance. A more recent 2015 meta-analysis of the relationship between corporate environmental performance and corporate financial performance also finds a positive effect, one that is amplified in more recent times (post-2000) in developed countries and the US, but is diluted in the BRIC countries of Brazil, Russia, India, and China and in other parts of Asia (Hang, Geyer-Klingeberg, Rathgeber, \& Stöeckl, In press). However, as with every aspect of sustainability, measuring the financial impact of sustainability initiatives is complex, often poorly done, and even more poorly communicated. In a recent study, $50 \%$ of executive respondents reported that they believed "the pressure of short-term earnings performance is at odds with sustainability initiatives," and only $25 \%$ reported that the financial benefits of sustainability programs were clearly understood throughout their organizations (Bonini \& Swartz, 2014: 9-10). The complexity is partially because some benefits may be longer term and indirect, such as improved company reputation and customer loyalty, making the measurement and communication aspects of financial impact difficult for companies to execute well. However, in a world where it is estimated that another 1.8 billion people will join the global consuming class by 2025 (representing a $75 \%$ increase over 2010 consumption data; Bové \& Swartz, 2016), that our students learn how to consider, create, measure, and then effectively communicate the financial benefits of sustainable business practices is imperative.

Our purpose here is not to review this voluminous literature. Rather it is just to give a snapshot of these studies, most of which have pointed to a positive relationship between sustainability and the corporate bottom line, but one that is not always unequivocal and one that typically hangs on a variety of contingencies. Despite these characteristics, it is important to highlight this perspective in teaching resources. Under some conditions, it does "pay to be good." But what are those conditions? How can they become more widespread? Given that most students who will be consuming teaching resources on sustainability ultimately will be operating within the confines of established businesses, there is a need to provide them with the evidence and tools to make the business case for sustainability.

More important than broad overall evidence are case studies. In our survey, instructors found cases to be the most important teaching tool for sustainability instruction with undergraduate students and the second most important resource (after academic papers) for teaching graduate and postgraduate courses. Cases are important because, although it may be true in general that sustainability can lead to a positive business outcome, this positive outcome does not hold in every instance. Achieving it requires long-term thinking, dedication, and patience. It rests on good management. Yet there is likely to be only trial-and-error support and enthusiasm for sustainability initiatives within individual companies: a pulling toward these goals and $a$ pulling away from them. It is rare that sustainability fully takes hold in any company, even missionbased firms such as Patagonia and Interface, or Whole Foods, sometimes deviate from this path. Understanding that positive intentions do not always yield positive results is a good takeaway lesson from any course on sustainability.

The movement toward sustainability is almost always a struggle for managers and firms; cases are useful because they illustrate this struggle and pinpoint when managerial choices and interventions can make a difference. In his 2015 book, 
Innovations in Sustainability: Fuel and Food, Marcus uses paired case studies to show that although progress has taken place in the sustainable journey, this same progress is often halting and unfinished. In the cases on venture capital and clean energy, Marcus' cases aptly illustrate that the lack of profitability ultimately slows venture capital investment in this sector. Yet his cases invite readers to engage in reflection about what the private equity VC firmsKhosla and $\mathrm{KPCB}$ - and what the corporate venture copital arms of Google and Intel could have done differently then and what they should do today. At the time the cases were written, although the organizations' investments in clean energy had slowed, they had not disappeared, and over time, some sectors had received more funding and some less. Given this state of affairs, when using this casebook students are put in a position of advising VCs about what they should do next. What types of clean energy commitments should they continue to have?

As another example, Marcus' book also has a paired case on the alternative transportation companies, Tesla and Better Place, which raised the bulk of their funding from venture capitalists. Such cases are ideal for instructional purposes in that they take students into the decision-making moment, suggest alternative routes that the management of young companies can take, provide for instances of success (Tesla) and failure (Better Place), and ask students to reflect on the reasons for these outcomes. The key in a discussion of this paired case is not only to distinguish between the different business models and strategies of Tesla and Better Place, but also to have students use this instructional resource to ponder what actions Tesla might take next. Its continued success is not guaranteed, and it has many important decisions in front of it. Are there lessons it can learn from the Better Place failure? Accompanying the case are excellent videos of TedTalks in which Elon Musk of Tesla and Shai Agassi of Better Place are included. Instructors can use these videos to make their teaching about clean energy more captivating. The videos give an added reality and validity to the case analysis for students. Interestingly, instructors of sustainability and management in our sample have rated videos as the second most important teaching resource for undergraduate students (after cases), and videos come first when instructors rate their satisfaction with different teaching resources.

Thus, the results of our survey suggest that instructors primarily want to see resources for teaching sustainability that include a strong moral imperative-the purpose should be to make a compelling case for global change for a better world. Yet instructors are also interested in using cases in sustainability that illustrate that it is possible, albeit difficult, to achieve business goals simultaneously while addressing global sustainability issues. The combination of moral imperative with the practicalities of business decision making are key components in the creation of good resources for teaching sustainability in management.

\section{"The combination of moral imperative with the practicalities of business decision making are key components in the creation of good resources for teaching sustainability in management."}

\section{FINDINGS FROM THE SURVEY ON TEACHING MANAGEMENT SUSTAINABILITY RESOURCES: WHERE WE ARE NOW}

\section{Methodology and Sample}

Seeking to learn more about the state of teaching resources for sustainability management, we carried out an online survey during the spring of 2016. The targeted population was all subscribers to the Academy of Management's ONE-L and SIM list serves (ONE-L members: 864; SIM-L members: 1549, with an unknown overlap among subscribers). We selected this population because of its focus on sustainability management research and teaching among the members of the Academy of Management. We circulated an invitation to complete the online survey through each of the email lists and a subsequent reminder 3 weeks later. We received 169 survey responses. We found no significant differences between the answers of respondents after the original invitation and those answering after the subsequent reminder. Considering the profile of our respondents, our results were a good exploratory description of the SIM and ONE members' views on teaching resources in in the field of management and sustainability.

Our sample of survey respondents has relatively high levels of university-level teaching experience, with an average of 13 years for general management 


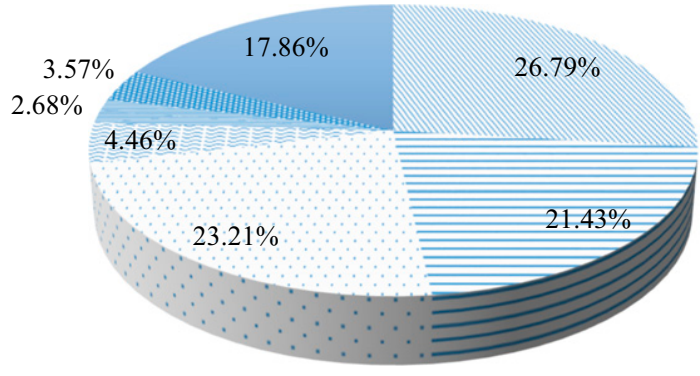
A. STRATEGY
$=$ B. GENERAL MANAGEMENT
C. CSR
$\therefore$ D. INTERNATIONAL BUSINESS
$\equiv \mathrm{E}$. HRM
F. OPERATIONS
$\approx$ G. OTHERS

FIGURE 1

Instructors Teaching Sustainability in Management Courses

and 10 years for sustainability management. Over $60 \%$ of our 169 respondents teach a course focusing mainly on sustainability management at either the undergraduate or graduate level (with $44 \%$ offering these courses at the graduate level). About $57 \%$ of our 169 respondents teach management courses that on average dedicate $30 \%$ of content to sustainability management topics. Figure 1 shows the fields from which the respondents come from in terms of the courses they teach. The largest respondent groups teach courses focused on strategy (27\%), general management (21\%), and corporate social responsibility (23\%).

\section{Results}

\section{Importance of Teaching Resources}

Respondents ranked the importance of the following resources for teaching management and sustainability: textbooks, cases, videos, databases, simulations, and games, academic journal papers, and mobile applications (apps), see Figure 2. We analyze separately the importance of the different teaching resources for undergraduate and graduate/ postgraduate students. Cases received the highest average importance score, 3.05 of 4 (where $0=$ not important at all and 4 = very important) for teaching

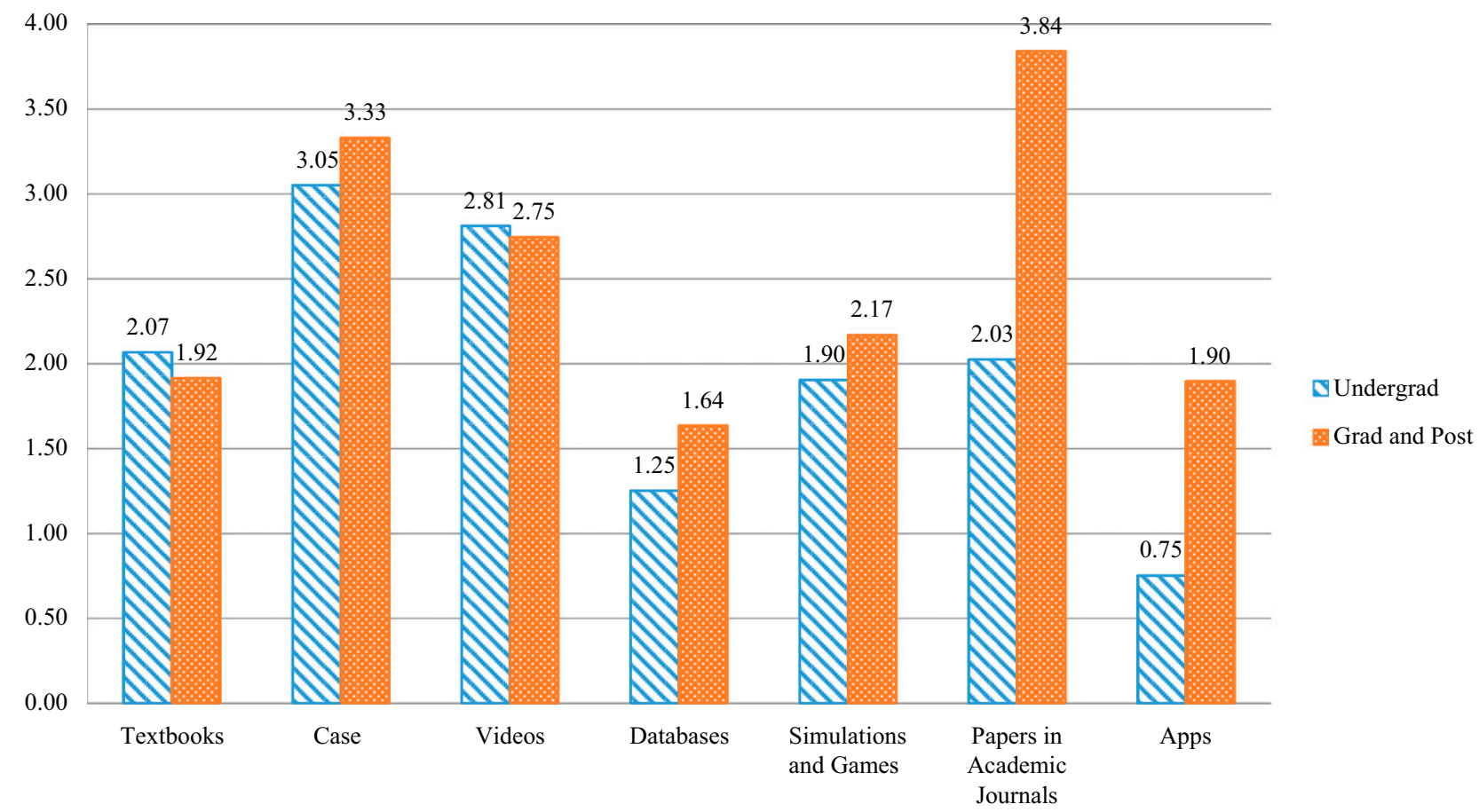

FIGURE 2

Importance of Different Teaching Resources (when teaching sustainability) 
undergraduate students. Indeed over $60 \%$ of respondents consider cases quite/very important. Videos have the second highest average importance scores at about 2.81 of 5 with about $50 \%$ of respondents considering videos quite/very importont. Textbooks, academic papers, and simulation and games show similar midlevels of importance for undergraduate instructors with an average score of approximately 2 of 4 .

Academic journal papers are the most important teaching resources for graduate and postgraduate instructors, with papers receiving the highest average importance score, 3.8 of 4 . Similarly to teaching undergraduate students, case studies and videos are also very important for teaching postgraduate students (3.38 and 2.81 of 4 , respectively). Simulation and games, textbooks, and databases show similar moderate levels of importance for postgraduate instructors. Apps showed the lowest mean importance score for undergraduate and postgraduate students, with only a few instructors using them in their teaching.

Also of interest, textbooks show a significantly higher $(p<0.05)$ level of importance for those teaching a general management course (3.2/5) than for those teaching a sustainability management course (2.58/5). Junior and senior instructors do not show significant differences when rating the importance of the teaching resources in the field.

\section{Satisfaction With Teaching Resources}

In terms of satisfaction with these different teaching resources, respondents show the highest average score levels, with journal papers at 2.92 of four $(0=$ very dissatisfied and $4=$ very satisfied), with $73 \%$ of our respondents indicating they are satisfied to very satisfied with academic journal articles as teaching resources in the field of management and sustainability. Videos (2.52/4) and cases (2.38/4) show the second and third highest average satisfaction scores, with about $50 \%$ of respondents indicating that they are satisfied to very satisfied with videos and cases. Databases show midlevels of average score satisfaction at about $2 / 4$. Textbooks (1.93/4), simulation and games (1.92/4), and apps (1.79/4) show the lowest levels of satisfaction, but the standard deviation is much higher for simulation and games and apps (suggesting highly different views among our respondents, with some of them very satisfied and others very skeptical) than for

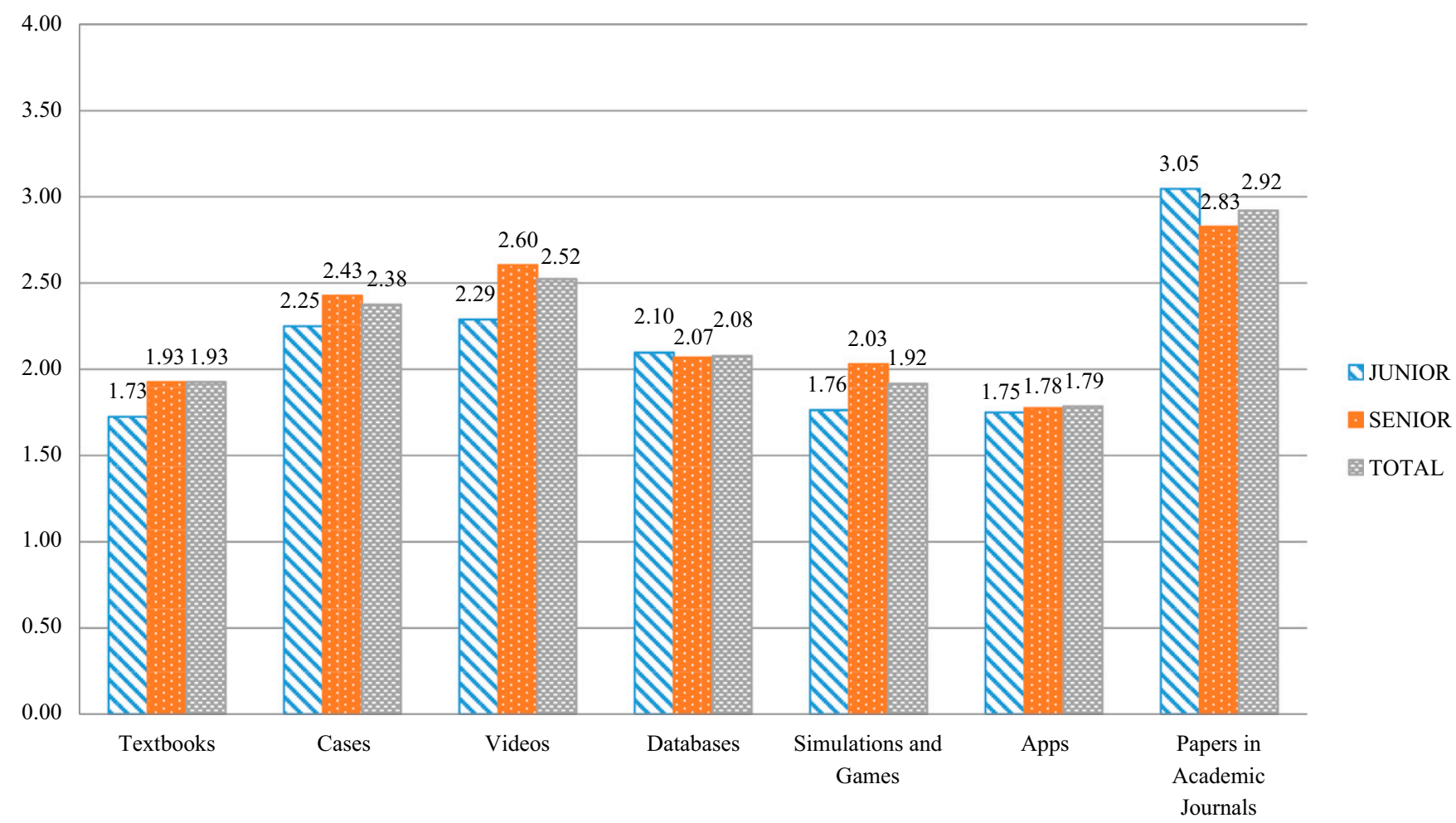

FIGURE 3

Satisfaction With Existing Sustainability Teaching Resources 


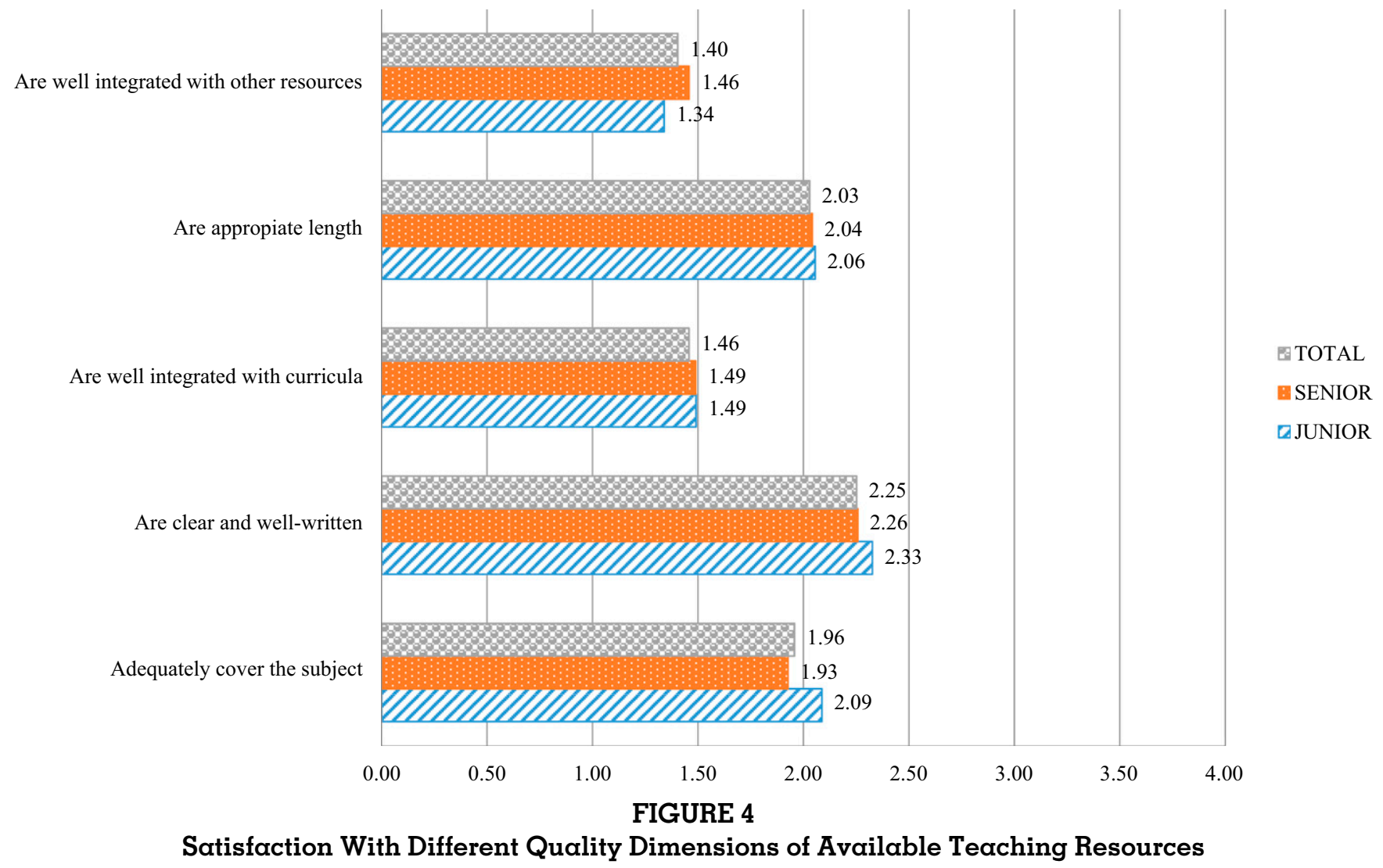

textbooks (most of respondents are similarly moderately satisfied to dissatisfied with existing textbooks).

Figure 3 also shows the satisfaction rate of junior and senior instructors as well as the overall satisfaction rate for all respondents separately (some respondents did not report how many years they have been teaching). In terms of differences between senior and junior faculty, senior instructors show higher satisfaction with the different teaching resources (i.e., they are more satisfied than junior instructors with videos, simulations, cases, and textbooks). However, junior instructors are more satisfied with papers in academic journals than are their senior counterparts. In any case, it is important to note that most of these differences between junior and senior instructors were not statistically significant, indicating that satisfaction levels with today's sustainability resources are similar for instructors regardless of teaching experience.

Respondents are mostly dissatisfied with the proposed quality dimensions of the teaching resources in this field (see Figure 4 for details). They expressed limited agreement (on a 0-4 scale, where $0=$ completely disagree and $4=$ completely agree), with the proposed statements suggesting satisfaction with the different quality dimensions. They ore especially unhappy with the limited integration of these teaching resources into the general curricula and other teaching resources available for instructors, and about $60 \%$ believe that teaching resources on sustainability are not well integrated with the curricula. "Length" is a reason for controversy, suggesting that instructors may have different preferences about the details to be offered in the different teaching resources. Last, they expressed moderate agreement with the clarity and writing of the resources (2.25 of 4) and the appropriate connection between the teaching resources and the subject (1.96 of 4).

The large majority of respondents (above 70\%) expressed strong agreement with "[t]he need for more and greater mix of teaching resources that are sustainability focused or that integrate sustainability dimensions into different management disciplines" (above 3 on 0-4 scale). Also interesting, the majority of respondents (64\%) indicated that they don't use textbooks more intensively when teaching sustainability management than when teaching general management courses; however, they feel that they use a bigger mix of resources when 
TABLE 1

Instructors' Expected Aims of Teaching Resources in the Field of Sustainability and Management

\begin{tabular}{|c|c|c|c|c|c|c|c|c|c|}
\hline & & \multicolumn{8}{|c|}{ Make companies better off by improving performance } \\
\hline & $\mathrm{NO}$ & 3 & $2.04 \%$ & 13 & $8.84 \%$ & 1 & $0.68 \%$ & 17 & $11.56 \%$ \\
\hline & Undecided & 3 & $2.04 \%$ & 6 & $4.08 \%$ & 9 & $6.12 \%$ & 18 & $12.24 \%$ \\
\hline & TOTAL & 64 & $43.54 \%$ & 49 & $33.33 \%$ & 34 & $23.13 \%$ & 147 & $100.00 \%$ \\
\hline
\end{tabular}

teaching sustainability-focused courses than when teaching general management.

\section{Purpose of Teaching Sustainability Resources}

Respondents tend to be divided about whether effective resources for teaching sustainability should specifically aim to make companies better off in terms of financial performance: $44 \%$ agree versus $33 \%$ disagree (23\% undecided). However, the large majority of respondents in our sample (76\%) do agree that effective sustainability teaching should specifically aim to change the world for the better (only $12 \%$ disagree; $12 \%$ are undecided). Of this group, only $52 \%$ also agree that teaching resources for sustainability should specifically aim to make companies better off in terms of financial performance. Conversely, $91 \%$ of those who agree that teaching sustainability resources should specifically aim to make companies better off in terms of financial performance also agree that these resources should specifically aim to change the world for the better. Table 1 shows details about these interesting differences.

Also, the proportion of junior professors (less than 8 years of academic experience) agreeing with the importance of teaching resources to change the world is marginally significantly higher than for senior professors $(p<0.10)$. In any case, the large majority of senior instructors also agree with that aim (with $68 \%$ of senior instructors and $86 \%$ of junior instructors believing resources should be aimed at changing the world for better). There was no significant difference between junior and senior professors with respect to the proportion agreeing that teaching resources should be aimed at increased company performance.

\section{FINAL REFLECTIONS ON TEACHING RESOURCES IN MANAGEMENT AND SUSTAINABILITY: WHERE WE GO FROM HERE}

Our results show how the instructors in business schools are still looking for appropriate teaching resources in the field of management, sustainability, and the natural environment. It is interesting that the respondents in this survey did not rate some of the most traditional teaching resources (e.g., available handbooks) as particularly useful. At the same time, it is exciting to see that digital resources (e.g., videos) are viewed as important and have relatively high associated levels of satisfaction for instructors in the field, even when Apps appear to be in a very early stage, and games or online simulators raise interest only for a limited group of our respondents. Cases also play a relevant role and are rated quite positively. Last, we are surprised that respondents report using academic papers quite intensively to teach in the field (particularly with postgraduate, but also with undergraduate students) and that they are also quite happy with the quality of these teaching resources. We wonder if satisfaction with academic papers occurs because these resources are usually relatively current and detailed or just because of instructor fomiliarity with the content. In any case, our results do not provide evidence about the effectiveness of each teaching resource; rather, they indicate instructors' self-reports of frequency of use and level of satisfaction.

Overall, it is important to note that instructors' satisfaction and perceived quality of the teaching resources in the field is only moderate. The respondents claim that a more integrated collection of different teaching resources would be more useful in teaching environmental and social dimensions of business activity than it would be in teaching general management. We feel that the complexity of sustainability issues, their roots in multiple and different fields (e.g., law, sociology, psychology, economics, engineering, and business management), and the difficulties of finding a balance between teaching sustainability to change the world for the better and to improve financial performance in firms generate difficulties in finding the proper teaching resources. As such, we offer 
a set of five recommendations-each stemming from an inherent challenge related to teaching sustainability - that we hope will guide the creation and evaluation of teaching and learning resources in this field:

\section{Teaching sustainability and learning resources must be highly cross-disciplinary in nature}

This requirement places a burden both on the faculty who teach and the students taking courses that either center on sustainability or incorporate sustainability into some of the course mater. Scientific, technical, political, policy, and social background information all must be available for students to fully comprehend the sustainability challenges that organizations face.

For example, for most businesses, understanding the Clean Air Act legislation that Congress first passed in the US in 1970 and subsequently amended in significant ways in 1977 and 1990 requires knowing about the seven criteria of pollutants the EPA mainly regulates, the harm that they cause, how awareness of this harm grew in the US and abroad through major incidents, how social movements and environmental activists organized to pressure Congress to pass the laws, and how businesses and trade associations approached the laws before they were passed and afterward. These laws affect microchip manufacturers such as Intel as well as large chemical companies such as Dow. The main solutions that companies can implement involve source reduction and pollution prevention as well as installing scrubbers and other pollution collectors at the end of their productions processes. Although there are national standards, each U.S. state has discretion to implement these laws in slightly different ways within the confines of the national framework. Whether these laws are effective depends on interactions with local pollution control officials.

With additional understanding, the danger of these criteria pollutants (e.g., fine particles likely to cause additional damage to a person's lungs), the laws have become stricter over time. The burden of compliance is felt much more by some sectors than others, for example coal mining. Utilities and independent power producers that sell electricity to utilities are thus limited in their choice of new power production projects.

The Clean Air Act, with all the complex scientific, technical, and legal issues is just one law that affects businesses that fall under the rubric of environmental statutes. There are also toxic pollution laws that test whether substances are safe, have the right to control their use, and to ban them outright if warranted. There are pesticide laws that govern corporate behavior in a very similar way. There also are laws governing the safety and recreational uses of water. There are laws that the EPA administers related to solid waste.

Understanding each of these, the politics that surround them, their technical and competitive implications, and the compliance burdens and costs is an immense undertaking. Responsibility for this undertaking falls on instructors who may have little policy, scientific, legal, or technical training. Yet without some introduction to these laws in the US and ideally, in other countries, a course about sustainability would be deficient. For business students, in particular, to get up to speed so that they can intelligently approach the challenges to business of environmental legislation in the US and abroad, and also as mandated by international governing organizations, for example the United Nations, is no easy task. Even the best students in a class who have strong backgrounds in relevant disciplines will feel stretched when confronted by the complexity of the legal, technical, and competitive challenges from different environmental domains.

2. Resources to teach sustainability need a broad approach and global scope, including not only of the environment and climate change, but also encompassing poverty, employment, workers' rights, jobs, and economic development in the faculty and students' home countries and, ideally, in other, often very different, countries.

Indeed, the environmental domain is just one of many that must receive coverage in a comprehensive sustainability course. Sustainability relates to the elimination of poverty, the reduction of inequality, the importance of education and health, the inclusion in organizations of a diverse and representative workforce. It relates to outsourcing practices that might lead to child labor, bad working conditions, the exploitation of women, diversity, and inclusion of people of different races and ethnic origins. These are global problems at the national level, and they manifest themselves nearly everywhere. Almost all major corporations are multinational in nature and will need people who are able to confront these challenges in multiple settings. 
As a result, effective teaching resources for sustainability management need to provide students with the knowledge of how the contextual differences between developing and industrialized countries affect business, government, and social groups' preferences and strategies. This involves understanding how the unique context of developing nations imposes distinctive limitations on and opportunities to design and implement innovative win-win sustainability management business strategies.

In typical developing countries, with lower levels of democracy and income per capita, businesses are expected to show more resistance to environmental and social responsibility demands and policies, yielding lower environmental and social performance. However, students also need to understand that the actual design of policies and strategies for managing sustainability may be more important than country characteristics. For example, Rivera's (2010) examination of the longterm implementation of two voluntary environmental certification programs-the U.S. ski industry's Sustainable Slopes Program and Costa Rica hotel industry's Certification for Sustainable Tourismsuggest that the opposite performance outcome can be possible: Costa Rica's program results in hotels' beyond-compliance behavior, whereas the U.S. ski industry program actually attracts players with lower environmental performance ratings. This counterintuitive result stems from fundamental differences in program design: The Costa Rican program is run by a government/business/ environmentalists' collaboration and includes thirdparty, performance-based certification that provides certified hotels with a price premium and sales benefits not available to uncertified hotels. On the other hand, The Sustainable Slopes Program is run by the U.S. ski industry, lacks third-party certification, involves no specific environmental standards, and has no sanctions for poor performance. The result is that green ski resorts tend to avoid this program, leaving mostly laggards seeking to greenwash their poor sustainability-management practices.

The global nature of business also means, for example, that bribery and corrupt practices both in the home country and the many other countries in which the company operates are elements of sustainability that require thoughtful examination. Corporate taxation and the avoidance of taxes by means of inversions are fair game in that these relate to the economic base of sustainability. Corporations throughout the globe are a major source of taxation for most governments, and they must pay their fair share if they are to operate in robust communities with strong infrastructures and educational opportunities. Corporations also cannot shirk their responsibilities for providing secure jobs and a healthy and safe workplace climate. These issues too claim their place in the pantheon of what can be legitimately covered in a sustainable course.

3. Sustainability discussions must involve asking not only fundamental questions (i.e., the "what" and "why" of sustainable practices), but also questions related to issues of effective implementation and outcome assessment (i.e., the "how" and "so what" of these practices).

Many major corporations are involved in charitable acts throughout the globe to enact sustainable practices such as providing clean drinking water to people where they operate, to eliminate disease, and to educate young men and women. To what degree, if at all, do these activities take away from the obligation corporations owe to their investors to maximize returns? Short-term versus long-term thinking bears on every question that is likely to be taken up in a sustainability course. How people find nourishment in the decades to come is also a sustainability challenge that falls on business as it does on citizens, governments, international agencies, and NGOs.

Another fundamental question that should be asked in a sustainability course is how much of corporate activity should be merely in the form of compliance with the law and how much should be beyond compliance: How much should corporations do in these realms because it is mandated and how much should they do voluntarily because it is their duty? How far should they be ahead of the evolving norms of society and to what degree should they just be keeping up with these norms? These questions are very complex. They go beyond simple discussions of stakeholder obligations and migrate to questions of strategy and identity.

A related question of equal importance is how much government and other organizations should be involved in tackling these issues along with the corporation. If the government is involved, what are likely to be most effective policy tools in different domains: direct regulation, subsidies, disclosure and transparency requirements, taxes, incentives, or the placing of value 
on pollution and the creation of markets for pollution trading?

There are so many pieces of the puzzle with sustainability issues that taking the students back to the basics of questions related to not only the "who, what, when, where, why, and how" components but also the "so what" of the situations may be a useful framework for the inevitable morass of information they discover.

4. Effective models for teaching sustainability require the inclusion of representative cases, vivid illustrations, and experiential learning.

Gaining rudimentary competencies in some if not all of these topics and in leading these activities will challenge most instructors. Gaining fullblown competencies in all of them is beyond the scope of any individual. Finding the right resources to teach sustainability means that instructors must be selective and find representative incidents, situations, and cases that can be relied upon to extract general lessons that might be applicable across these many domains. It also necessitates that instructors make these connections and that they urge and direct students to think systematically not only about one domain, but also about the web of issues that constitute the broad and generally accepted definition of sustainability. Case studies and videos have already gained momentum in the teaching of management and sustainability, and they will probably be even more important in the future. We feel that electronic resources (e.g., mobile apps) will also help to provide convenient and effective resources to teach in this field, even though are still in a very early stage. The growing importance of big data in society as it relates to sustainability (Etzion \& Aragon-Correa, 2016) will also probably reinforce the interest of using databases to teach sustainability.

Corporations clearly cannot achieve the goals of sustainability alone, and thus, a course also must focus on partnership, alliances, and negotiations with organized and unorganized groups outside the corporation, with groups that recognize the corporation and its rights, and groups that would like to sweep away all corporations from functioning. Thus, negotiation is also a topic that a sustainability course cannot ignore, with negotiation cases serving as a useful tool for creating engaging and informed experiential interactions. Involving students in projects with their communities, both locally and internationally, through student trips and special projects outside the university and throughout the world should also, wherever possible, be an element in the design of teaching sustainability.

\section{Sustainability resources must include a clear} focus and concern for business success and failure.

Of course, if businesses do not survive it is not possible to achieve sustainability goals given the way the world is currently constructed. Thus, considerable emphasis must be placed on how sustainability strategies and projects contribute to, or at least do not detract from, the bottom line. For managers to engage in the debate within their organizations about whether particular sustainable projects should be undertaken, they must be armed with analytical tools and reasoning capabilities to make a strong business case for sustainability. Otherwise, as we continue to see all too often, organizational decision makers will use the justification that if a particular project has no financial return, it is simply is not worth doing. Moral suasion is important, but not sufficient.

Prominent examples of companies with strong sustainability strategies and commitments such as Patagonia and Tesla can have a central place in a sustainability course, as they seem to show that sustainability is a central part of their business model that allows them to strive and achieve financial returns. Instructors can stimulate debates among their students about the degree to which firms like this and others are genuinely sustainable, or to which they are using sustainability as a wedge to win business from a well-educated, advanced, health-conscious, and otherwise progressive slice of the population. Useful questions include the following: "Do firms that try to stand out as sustainable ventures really meet a rigorous test of sustainability?" "To what extent do their actions and behaviors fall short?" "To what extent do companies not especially well-known actually surpass them in the impacts of their activities on people and planet as well as the corporate bottom line?"

Contrasting well-intentioned corporations with others that have breached the social contract by allowing disasters or scandals to take place is a useful activity in any sustainability course. Companies such as Whole Foods, Walmart, Monsanto, DuPont, BP, ExxonMobil, Wells Fargo, and Goldman Sachs make for compelling case analyses and debate: "Have they made sufficient amends for actions in which they once engaged?" "Are they the good citizens that they now claim to 
be?" "If not why?" "What is the real balance for any corporation between the good it tries to do versus the very serious harm that it may sometime cause?"

What about the likely promise of large returns that motivated venture capitalists to both plunge deeply into clean energy and then almost equally as quickly move out as it became increasingly apparent that they could not earn the large returns that they were seeking? This dipping into and out of sustainability manifests itself among many business ventures and begs the question of whether sustainability just a fad, in place to enhance corporate reputation and legitimacy, or is it a new and permanent way of doing business that has the potential to transform capitalism?

The answer lies somewhere in the middle. Working with students to arrive at a nuanced approach to the ups and downs of corporate sustainability is another worthy aim in teaching any sustainability course. Achieving this aim will require its own sets of resources that allow students to go beyond the moment and examine the dynamics of the journey over time.

There can be no doubt that creating an effective teaching-and-learning experience of sustainability in the management domain is difficult. It is overwhelmingly complex in that it is multidisciplinary, multitopic, multi-issue, and multinational. It is certainly not for the faint-hearted. It is also, however, unassailable in terms of its importance to our future. We have to do this, and we have to do it well. To move forward in the domain of sustainability in management education, there is a good deal of work that needs to be done in terms of creating effective teaching and learning resources. Part of this work will involve looking at existing resources in new ways, part will involve adaptation and change, and part will involve creation and innovation. We do not purport to have all the answers, in fact, we have more questions than answers. It is in this vein that we recognize the importance of our own continuous learning and experimentation with a variety of teaching resources and media as well as the importance of our shared learning and open communication with our students.

To help move the field forward, we share this essay drawing upon our shared experiences, our passion for the domain, and a combined longstanding history of teaching in sustainability. Here, we have presented our current assessment of the field, as well as five recommendations, each stemming from an inherent challenge in teaching sustainability, which we believe are critical to the design and development of effective teaching resources in this domain. In summary, teaching management sustainability and learning resources need to be: (1) cross-disciplinary; (2) broad in scope; (3) grounded in a comprehensive set of questions about design, implementation, and outcomes; (4) representative, engaging, and vivid; and (5) inclusive of issues related to business success and/ or failure. It is our hope that our comments, coupled with the thoughtful responses of 169 sustainability instructor colleagues and the well-written resource reviews found in the BRR section of this $A M L E$ issue, will invigorate examination and adaptation of existing resources as well as inspire the creation of targeted and innovative teaching and learning resources across a wide variety of media and communication platforms.

\section{REFERENCES}

Bonini, S., \& Swartz, S. 2014. Profits with purpose: How organizing for sustainability can benefit the bottom line. McKinsey on Sustainability and Resource Productivity, Vol. 2: 5-15. Retrieved from: http://www.mckinsey.com/business-functions/ sustainability-and-resource-productivity/our-insights/profitswith-purpose-how-organizing-for-sustainability-can-benefitthe-bottom-line. Accessed on July 21, 2017.

Bové, A., \& Swartz, S. 2016. Starting at the source: Sustainability in supply chains. McKinsey on Sustainability and Resource Productivity, Vol. 4: 36-43. Retrieved from: http://www. mckinsey.com/business-functions/sustainability-and-resourceproductivity/our-insights/starting-at-the-source-sustainability-in-supply-chains.

Buzby, J. C., \& Hyman, J. 2012. Total and per capita value of food loss in the United States. Food Policy, 37(5): 561-570.

Delgado-Ceballos, J., Aragón-Correa, J. A., Ortiz-de-Mandojana, N., \& Rueda-Manzanares, A. 2012. The effect of internal barriers on the connection between stakeholder integration and proactive environmental strategies. Journal of Business Ethics, 107(3): 281-293.

Dreibelbis, C. 2013. Putting a dollar value on food waste estimates. Posted on December 20, 2013 at 2:20pm. Retrieved from: http:// blogs.worldwatch.org/nourishingtheplanet/putting-a-dollarvalue-on-food-waste-estimates/ Accessed on November 26, 2016.

Dyllick, T. 2015. Responsible management education for a sustainable world. Journal of Management Development, 34(1): 16-33.

Eccles, R. G., Ioannou, I., \& Serafeim, G. 2014. The impact of corporate sustainability on organizational processes and performance. Management Science, 60(11): 2835-2857.

Etzion, D., \& Aragon-Correa, J. A. 2016. Big Data, management, and sustainability strategic opportunities ahead. Organization \& Environment, 29(2): 147-155. 
Food and Agriculture Organization of the United Nations. 2016. Presentation titled, "The State of Food and Agriculture: Climate Change, Agriculture, and Food Security." Published online on October 17, 2016. Retrieved from: http://www.slideshare.net/FAOoftheUN/the-state-of-food-and-agriculture2016-67283022. Accessed on November 4, 2016

Gardner, G., \& Halweil, B. 2000. Underfed and overfed: The global epidemic of malnutrition. Washington, DC: Worldwatch Institute.

Hang, M., Geyer-Klingeberg, J., Rathgeber, A., \& Stöeckl, S. (In press). Economic development matters: A meta-regression analysis on the relation between environmental management and financial performance. Journal of Industrial Ecology. Available ahead of print online at http://onlinelibrary. wiley.com/doi/10.1111/jiec.12573/full.

Hart, S. L. 1997. Beyond greening: Strategies for a sustainable world. Harvard Business Review, 75(1): 66.

Hart, S., Sharma, S., \& Halme, M. 2016. Poverty, business strategy, and sustainable development. Organization \& Environment, 29(4): 401-415.

Laughland, P., \& Bansal, T. 2011. The top ten reasons why businesses aren't more sustainable. Ivey Business Journal, Jonuary-February. Retrieved from: http://iveybusinessjournal. $\mathrm{com} /$ publication/the-top-ten-reasons-why-businesses-arentmore-sustainable/.
London, T. 2016. The base of the pyramid promise: Building businesses with impact and scale. Stanford University Press.

Marcus, A. A. 1995. Business and society: Strategy ethics and a global economy. Richard Irwin.

Margolis, J. D., Effenbein, H. A., \& Walsh, J. P. 2011. Does it pay to be good ... and does it matter? A meta-analysis of the relationship between corporate social and financial performance. SSRN Working Paper Series.

Porter, M. E., \& Vanderlinde, C. 1995. Green and competitiveEnding the stalemate. Harvard Business Review, 73(5): 120-134.

Prahalad, C. K., \& Hart, S. L. 2002. The fortune at the bottom of the pyramid. Strategy +Business, 26: 54-67.2.

Rivera, J. 2010. Business and public policy: Responses to environmental \& social protection processes. Cambridge, UK: Cambridge University Press.

Unruh, R., Kiron, D., Kruschwitz, N., Reeves, M., Rubel, H., Meyer, A., \& Felde, Z. 2016. Investing for a sustainable future. MIT Sloan Management Review, May llst.

Van der Byl, C. A., \& Slawinski, N. 2015. Embracing tensions in corporate sustainability. A review of research from win-wins and trade-offs to paradoxes and beyond. Organization \& Environment, 28(1): 54-79.

J. Alberto Aragon-Correa is a professor of strategy at University of Granada (Spain) and Research Honorary Professor of Management at University of Surrey (UK). He has published in multiple journals on the implications and antecedents of environmental business strategies. He is currently working in how innovations and information technologies matter in the sustainability field.

Alfred Marcus is professor and Spencer Chair in Strategy and Technological Leadership University of Minnesota Carlson School of Management and the Technological Leadership Institute. $\mathrm{He}$ is the author of Innovations in Sustainability, Cambridge University Press, the Academy of Management ONE 2016 Outstanding Book Award. In 2016, he published The Future of Technology Management and the Business Environment.

Jorge E. Rivera, $\mathrm{PhD}$ Duke University, professor of strategic management and public policy, Tucker Endowed Fellow, The George Washington University's School of Business. His current business interest is environmental management and policy.

Amy Kenworthy is a professor of management at Bond University in Queensland, Australia. She received her PhD in organizational behavior from the University of North Carolina at Chapel Hill. Her primary research and scholarship interests are focused on the interrelated areas of servicelearning, community engagement, and experiential education practices. 